\title{
Optimizing quality of care by patient satisfaction for the department of orthopedics - a survey study
}

\author{
Milad Modarresi, MD', Ammar Qureshi, MD', Rodrigo Aguilar, MD', \\ Meghan Anderson, BS ${ }^{1}$, Felix Cheung, MD'
}

ABSTRACT

INTRODUCtION: Hospital Consumer Assessment of Healthcare Providers and System (HCAHPS) has provided a standardized survey method in order to evaluate patient's satisfaction on the care provided. While overall patient satisfaction is clearly a multidimensional concept, the HCAHPS survey covers eight domains of health care. This study tries to identify and establish the main determinants to patients' levels of satisfaction during their visits to Cabell Huntington Hospital orthopedics department.

METHODS: Data was collected from surveys handed out in three consecutive months: June, July and August of 2013. Sixteen questions were selected from HCAHPS that were appraised to be relevant for the use in orthopedics department. The main dependent questions that allowed patients to rate their overall satisfaction were (1) how much is the patient likely to recommend the department and (2) how would they rate their overall satisfaction in their visits. We then studied each of the other fourteen questions (independent questions) the patients were made to answer and how much they determined the overall patient satisfaction. We also divided the questionnaire into those questions the health care provider had control over (modifiable) and those where that were not under their control (non-modifiable). Data was then gathered and step-wise multi variable regression analysis was performed. All analyses were performed using SAS version 9.3.

RESULTS: 138 patients answered the survey. The independent question that had the maximum impact on the overall patient satisfaction was whether the nurses treated them with respect $(\mathrm{OR}=11.5,95 \% \mathrm{Cl} 3.1-43.12$.

CONCLUSION: We determined that how the nurses treat the patients and whether the doctors listened to their patients carefully had the highest impact on determining patients' overall satisfaction and their likelihood of recommending the doctors to their relatives or friends. Our study outlines that the patients' experiences of their visits to the orthopedic office is dependent on a variety of factors, which can be modified by the healthcare providers in order to improve the patient's satisfaction.

\section{KEYWORDS}

patient satisfaction; HCAHPS; questionnaire

\section{INTRODUCTION}

Survey questionnaires are able to cover variety of subject matters and are ideal for achieving a higher target number of population..$^{1-3}$ Hospital Consumer Assessment of Healthcare Providers and System
Author affiliations are listed at the end of this article.

Correspondence to: Milad Modarresi, MD Marshall University Joan C. Edwards School of Medicine modarresi@marshall.edu 
of the survey questions and answers, so results can be compared between hospitals. The HCAHPS data is used to evaluate the level of hospital care and can be used to improve decision making.

Patient satisfaction is important for consumer relations. Many studies have noted socioeconomic and racial differences when reporting patient satisfaction. ${ }^{14}$ Patient satisfaction studies can be used to identify which aspects of patient care are related to hospital performance indicators and how they can be improved.

Overall patient satisfaction is a multidimensional concept. Factors affecting patient's rating of a specific visit encounter can have confounding factors, and may be influenced by aspects such as age, educational background, and patient expectations apart from the medical encounter itself. Other variables include overall health, medical staff encounters, and financial status.

This study attempted to identify and establish the primary reasons for patients' levels of satisfaction during their visit to Cabell Huntington Hospital orthopedic surgery department. Analysis of data gathered from surveys shows there are multiple factors that could influence a patient's level of satisfaction. Furthermore, some factors might have a larger impact than others.

\section{METHODS}

Data was collected from surveys distributed during three consecutive months: June, July, and August of 2013. For one week each month, all patients seen in the Cabell Huntington Hospital Orthopedic Clinic were given a survey at the end of their visit. Fifteen questions were selected from the Hospital Consumer Assessment of Healthcare Providers and Systems
(HCAHPS) that were appraised to be relevant for the use in the orthopedic department (Table 1).

Questions 1-10 covered three domains of patient care: communication with physicians, communication with nurses, and quality of the nursing services. Questions 11-13 covered patient specific demographics. Questions 15 and 16 rated the overall patient experience of the entire encounter. Question 14 was not relevant to an orthopedic visit and therefore omitted. Patients were asked to fill out the survey after the visit but before leaving the office.

Questions 1-13 were also divided based on whether they were modifiable or non-modifiable. Questions 1-10 were defined as factors that could be changed

\begin{tabular}{|c|c|c|}
\hline Number & Question & Legend \\
\hline 1 & Did the nurses treat you with respect? & \multirow{8}{*}{$\begin{array}{l}\text { 1-Never } \\
\text { 2-Sometimes } \\
\text { 3-Usually } \\
\text { 4-Always }\end{array}$} \\
\hline 2 & Did the nurses listen to you carefully? & \\
\hline 3 & Did the nurses explain thing well? & \\
\hline 4 & $\begin{array}{l}\text { How prompt was the help using the } \\
\text { office telephone? }\end{array}$ & \\
\hline 5 & Did the doctors treat you with respect? & \\
\hline 6 & $\begin{array}{l}\text { Did the doctors listen to you } \\
\text { carefully? }\end{array}$ & \\
\hline 7 & Did the doctors explain things well? & \\
\hline 8 & $\begin{array}{l}\text { Did the front desk staff treat you with } \\
\text { respect? }\end{array}$ & \\
\hline 9 & Were your preferences considered? & \multirow{2}{*}{$\begin{array}{l}\text { 1-Strongly Agree } \\
\text { 2-Disagree } \\
\text { 3-Agree } \\
\text { 4-Strongly Agree }\end{array}$} \\
\hline 10 & $\begin{array}{l}\text { I understand my responsibilities for } \\
\text { managing my health. }\end{array}$ & \\
\hline 11 & Patient rating overall health. & \multirow{2}{*}{$\begin{array}{l}\text { 1-Poor } \\
2 \text {-Fair } \\
3 \text { - Good } \\
4 \text { - Very Good } \\
\text { 5-Excellent }\end{array}$} \\
\hline 12 & $\begin{array}{l}\text { Patient rating overall } \\
\text { mental/emotional health. }\end{array}$ & \\
\hline 13 & Highest level of school completed. & $\begin{array}{l}\text { 1- } 8^{\text {th }} \text { grade of less } \\
2 \text { - Some high school, did not graduate } \\
\text { 3- High school graduate or GED } \\
\text { 4-Some college or 2-year degree } \\
\text { 5--More than 4 years of college }\end{array}$ \\
\hline 15 & $\begin{array}{l}\text { Would you recommend us to } \\
\text { family/friends? }\end{array}$ & $\begin{array}{l}\text { 1-Definitely No } \\
\text { 2-Probably no } \\
\text { 3-Yes } \\
\text { 4-Definitely Yes }\end{array}$ \\
\hline 16 & Rate your overall visit. & $\begin{array}{l}\text { On a scale of } 1-10 ; 10 \text { being most } \\
\text { satisfied and } 1 \text { not being satisfied at all. }\end{array}$ \\
\hline
\end{tabular}

TABLE 1 Questions presented in the questionnaire *Question 14 was omitted from calculations due to lack of any significance to orthopedic patients. 
from the healthcare provider's perspective. Doctors, nurses, and front desk variables were the ones that have the ability to be altered. On the other hand, non-modifiable variables (questions 11-13) are variables we have no control over, such as patient education or how they rate their own health. These two groups were analyzed as subgroups.

We were most interested in seeing which of the first thirteen questions affected Questions 15 and 16 (measures of overall satisfaction with the visit). We dichotomized the results of those two questions, comparing those who gave a 4 / 4 score for Question 15 with those who did not, and those who gave a 9 or 10 out of 10 score for Question 16 with those who did not. This was cross referenced with each of the other questions. All categorical variables were compared using Pearson's $X 2$ test. Questions 15 and 16 underwent stepwise multivariable regression analysis, with a sub group analysis. All analyses were performed using SAS version 9.3 (SAS Institute, Cary, North Carolina). All p-values were based on 2-sided tests and were considered statistically significant when $p<0.05$.

\section{RESULTS}

A total of 1,138 patients were asked to answer the survey. The response rate was $66 \%$. Table 2 depicts the impact of the answers to questions 1 through 13 on the patients' overall satisfaction after stepwise multivariable regression analysis. Questions 1, 4, 6, 10, and 12 had the maximum impact on the overall satisfaction based on the odds ratio as shown in Table 3. These questions, in order of impact level, were whether patients felt as if they were treated with respect by nursing staff (Question 1 (8.90\% versus $91.05 \%, \mathrm{p}<0.0001$; OR $11.5,95 \% \mathrm{Cl}=3.1-43.12)$ ), how much the patient understood their responsibilities towards managing their own health (Question 10 (5.67\% versus 94.33\%, $p<0.0001$;
OR $4.302,95 \% \mathrm{Cl}=2.43-7.61)$ ), how well they felt that the doctors listened to them (Question 6 (8.41\% versus $91.59 \%, \mathrm{p}<0.0001$; OR $4.223,95 \% \mathrm{Cl}$ $=1.48-12)$ ), how prompt was the help while using the telephone (Question 4 (5.85\% versus $94.15 \%$, $\mathrm{p}<0.0001$; OR $2.26,95 \% \mathrm{Cl}=1.57-3.24)$ ), and how the patient rated their own mental/emotional health (Question 12 (3.8\% versus 96.2\%, $\mathrm{p}<0.0001$; OR 1.93, $95 \% \mathrm{Cl}=1.47-2.54)$ ).

Analysis was done on Question 15, which rated how likely patients were to recommend the service to friends and/or family. Impact of the answers to other questions on Question 15 are shown in Table 4. It was discovered that answers to questions $4,6,9,10$, 11 had the most significant effect on the likelihood of being recommended by the patient to their family and/or friends (Table 5). These questions, in order of impact, were whether the patient felt that their doctors listened to them carefully (Question 6 (91\% vs $9 \%, \mathrm{p}=<0.0001$; OR $4.04,95 \% \mathrm{Cl}=1.54-10.62)$ ), whether their preferences were taken into account (Question 9 95.07\% vs 4.93\%, $\mathrm{p}=<0.0001$; OR 2.36,

\begin{tabular}{|c|c|c|c|}
\hline Analyzed to & $\begin{array}{c}\text { Q16 Answers 1-8; } \\
\text { and number of } \\
\text { patients in this } \\
\text { group }(=\mathrm{n})\end{array}$ & $\begin{array}{c}\text { Q16 Answers 9 \& } \\
\text { 10; and number of } \\
\text { patients in this } \\
\text { group (=n) }\end{array}$ & P-Value \\
\hline Q1 & $8.95 \%(95)$ & $91.05 \%(966)$ & $<0.0001$ \\
\hline Q2 & $8.26 \%(86)$ & $91.74 \%(955)$ & $<0.0001$ \\
\hline Q3 & $8.45 \%(87)$ & $91.55 \%(943)$ & $<0.0001$ \\
\hline Q5 & $5.85 \%(37)$ & $94.15 \%(596)$ & $<0.0001$ \\
\hline Q6 & $9.12 \%(96)$ & $90.88 \%(957)$ & $<0.0001$ \\
\hline Q7 & $8.41 \%(87)$ & $91.59 \%(947)$ & $<0.0001$ \\
\hline Q9 & $8.94 \%(92)$ & $91.06 \%(937)$ & $<0.0001$ \\
\hline Q10 & $8.49 \%(86)$ & $91.51 \%(927)$ & $<0.0001$ \\
\hline Q11 & $5.54 \%(42)$ & $94.46 \%(716)$ & $<0.0001$ \\
\hline Q12 & $5.67 \%(47)$ & $94.33 \%(782)$ & $<0.0001$ \\
\hline Q13 & $5.15 \%(17)$ & $94.85 \%(313)$ & $<0.0001$ \\
\hline & $3.80 \%(14)$ & $96.20 \%(354)$ & $<0.0001$ \\
\hline
\end{tabular}

TABLE 2 Effect of questions 1 through 13 on overall patient satisfaction (Question 16)

\begin{tabular}{|l|l|l|l|l|}
\hline & $\begin{array}{l}\text { Q16 Rating of } \\
\mathbf{1 - 8} \mathbf{( \% )}\end{array}$ & $\begin{array}{l}\text { Q16 Rating of } \\
\mathbf{9 - 1 0}(\%)\end{array}$ & p Value & OR (95\% CI) \\
\hline Q1 "Did the nurses treat you with respect" & 8.90 & 91.05 & $<0.0001$ & $11.5(3.1-43.12)$ \\
\hline $\begin{array}{l}\text { Q10 "I understand my responsibilities for } \\
\text { managing my health }\end{array}$ & 5.67 & 94.33 & $<0.0001$ & $4.30(2.43-7.61)$ \\
\hline Q6 "Did the doctors listen to you carefully" & 8.41 & 91.59 & $<0.0001$ & $4.22(1.48-12)$ \\
\hline $\begin{array}{l}\text { Q4 "How prompt was the help using the } \\
\text { office telephone" }\end{array}$ & 5.85 & 94.15 & $<0.0001$ & $2.26(1.57-3.24)$ \\
\hline $\begin{array}{l}\text { Q12 "Patient rating of overall } \\
\text { mental/emotional health" }\end{array}$ & 3.8 & 96.2 & $<0.0001$ & $1.93(1.47-2.54)$ \\
\hline
\end{tabular}

TABLE 3 Questions having the maximum impact on overall satisfaction based on odds ratio (Question 16) 
$95 \% \mathrm{Cl}=1.11-4.99)$, how well the patient understood the responsibilities in managing their own health (Question 10 (94.05\% vs 5.95\%, $p=<0.0001$; OR $2.293,95 \% \mathrm{Cl}=1.11-4.73)$ ), the patients rating of their overall own health (Question 11 (94.05\% vs $5.95 \%, \mathrm{p}=<0.0001 ; \mathrm{OR} 2.293,95 \% \mathrm{Cl}=1.11-4.73)$ ), and how prompt they felt the help from the office telephone was (Question $4(93.30 \%$ vs $6.7 \%, p=$ $<0.0001$; OR 1.636, 95\% Cl=1.11-2.4)).

Modifiable \& Non-MOdifiable factors

After stepwise multi-variable regression analysis, we found modifiable questions affecting question 16 (overall satisfaction) were questions 1 (OR 11.5, $95 \% \mathrm{Cl}=3.1-43.12), 10$ (OR 4.30, 95\% Cl= 2.43-7.61), 6 (OR $4.22,95 \% \mathrm{Cl}=1.48-12)$ and $4(\mathrm{OR} 2.26,95 \% \mathrm{Cl}=$ 1.57-3.24). Non-modifiable factors affecting overall satisfaction was depicted by question 12 (OR 1.93, $95 \% \mathrm{Cl}=1.47-2.54)$.

With regard to question 15 (if the patient was likely to recommend the office to their family or friends), modifiable questions affecting it were questions 6 (OR 4.04, 95\% Cl= 1.54-10.62), 9 (OR 2.36, 95\% Cl= 1.11-4.99), 10 (OR 2.29, 95\% $\mathrm{Cl}=1.11-4.73$ ) and 4 (OR $1.63,95 \%=1.11-2.4)$. The non-modifiable factors affecting question 15 was question 11 (OR 1.76, 95\% $\mathrm{Cl}=1.31-2.36)$.

\section{DISCUSSION}

This study was conducted in order to evaluate the factors influencing patient satisfaction in the outpatient orthopedics service at Cabell Huntington Hospital. Analysis of our data demonstrated that all the questions answered by patients proved to have a significant effect on how they rated their overall visit. The fact that questions 1, 6 and 10 had the highest correlation with a high score on overall satisfaction (Question 16) meant that

\begin{tabular}{|c|c|c|c|}
\hline Analyzed to & $\begin{array}{c}\text { Q15 Answers 1-3; } \\
\text { and number of } \\
\text { patients in this } \\
\text { group }(=n)\end{array}$ & $\begin{array}{c}\text { Q15 Answer 4; and } \\
\text { number of patients } \\
\text { in this group (=n) }\end{array}$ & P-Value \\
\hline Q1 & $9.94 \%(108)$ & $90.06 \%(978)$ & 0.18 \\
\hline Q2 & $8.95 \%(95)$ & $91.05 \%(967)$ & $<0.0001$ \\
\hline Q3 & $9.23 \%(97)$ & $90.77 \%(954)$ & $<0.0001$ \\
\hline Q4 & $6.7 \%(43)$ & $93.30 \%(599)$ & $<0.0001$ \\
\hline Q5 & $9.78 \%(105)$ & $90.22 \%(969)$ & $<0.0001$ \\
\hline Q6 & $9 \%(95)$ & $91 \%(961)$ & $<0.0001$ \\
\hline Q7 & $9.61 \%(101)$ & $90.39 \%(950)$ & $<0.0082$ \\
\hline Q8 & $9.65 \%(100)$ & $90.35 \%(936)$ & 0.1785 \\
\hline Q10 & $4.93 \%(38)$ & $95.07 \%(733)$ & $<0.0001$ \\
\hline Q11 & $5.95 \%(50)$ & $94.05 \%(791)$ & $<0.0001$ \\
\hline Q12 & $7.78 \%(26)$ & $92.22 \%(308)$ & $<0.0001$ \\
\hline Q13 & $11.36 \%(40)$ & $88.64 \%(312)$ & $<0.0001$ \\
\hline
\end{tabular}

TABLE 4 Effects of questions 1 through 13 on the likelihood of recommending us to their relatives/friends (Question 15)

office staff have influence over. The non-modifiable factors that played a role in patient satisfaction were mental health (Question

\begin{tabular}{|l|l|l|l|l|}
\hline & $\begin{array}{l}\text { Q15 Rating } \\
\text { of 1-3 (\%) }\end{array}$ & $\begin{array}{l}\text { Q15 Rating } \\
\text { of 4 (\%) }\end{array}$ & p Value & OR (95\% CI) \\
\hline Q6 "Did the doctors listen to you carefully" & 9 & 91 & $<0.0001$ & $4.04(1.54-10.62)$ \\
\hline Q9 "Were your preferences taken into account" & 4.93 & 95.07 & $<0.0001$ & $2.36(1.11-4.99)$ \\
\hline $\begin{array}{l}\text { Q10 "I understand my responsibilities for my } \\
\text { managing my own health" }\end{array}$ & 5.95 & 94.05 & $<0.0001$ & $2.29(1.11-4.73)$ \\
\hline Q11 "Patient rating overall health" & 7.78 & 92.22 & $<0.0001$ & $1.76(1.31-2.36)$ \\
\hline $\begin{array}{l}\text { Q4 "How prompt was the help using the office } \\
\text { telephone" }\end{array}$ & 6.7 & 93.30 & $<0.0001$ & $1.63(1.11-2.4)$ \\
\hline
\end{tabular}
12) and overall health (Question 11), which had much lower impact on results.

Studies have shown data from HCAHPS to have a

TABLE 5 Questions having the maximum impact on the likelihood of being recommended to friends/family (Question 15) positive correlation between patient experiences and quality of clinical care. ${ }^{5,6}$ In a cross-sectional study by Marshall et al., it was demonstrated that there is an association with mental health and general patient satisfaction. ${ }^{7}$ Nursing shortages 
have been associated with a lower level of patient satisfaction, which according to our data, should have massively impacted the overall score. ${ }^{8}$ One of the most identified variables that could have a major effect on a patient's rating was found to be patient's expectation of their results and treatment., ${ }^{1,2}$ This effect was found to be nullified by discussion and explanation of the procedure, treatment course, and results by the provider and health staff.

Another study by Fenton et al. found that patients who were most satisfied had less emergency department use, but a greater chance of being admitted, a higher healthcare and prescription cost, and a higher mortality rate. ${ }^{9}$ Moreover, more satisfied patients had better average physical and health status as compared to less satisfied patients. Studies by Giordano et al. and Bickell et al. have reported higher scores in more affluent communities and difference in scores when race was added to the question. ${ }^{10,11}$ Our study did not stratify the population according to the race and socioeconomic status, although in our survey there was no correlation between education level and satisfaction. Another factor that cannot be objectified by these questionnaires is the patient's emotions and state of mind, where some of them are more trusting of their providers and hence report a higher score., ${ }^{9,12}$ There are concerns whether patient satisfaction should be used to evaluate healthcare. Some questions can skew the results against the standard of medical care, especially in cases where there are a higher proportion of mentally ill patients. ${ }^{13}$ Mental health, as shown in this study, is considered an independent factor that has an effect on patient's overall referral rate of service.

Limitations in the study include having taken the survey in the doctor's office with doctors and staff being present; this could have possibly led to halo effect bias (patients having answered questions in a way to satisfy the physician). Another limitation of this study is the selection of specific questions from the HCAHPS original survey. These questions were selected and taken out of the order presented in HCAHPS and as a result they cannot be considered completely standardized.

A selection bias might have occurred since calculations are based on the patients who chose to respond to questions. Patients who are not satisfied or very satisfied might be more inclined to provide their feedback as compared to those who are in between.

In summary it appears that while there are nonmodifiable patient related factors, like patients mental and overall health, there are factors that clinics can have a direct effect on (i.e. doctors listening to patients, nurses treating patients with respect, effective communication with the patients). Future studies planned include looking at phone surveys done in a neutral setting and linking satisfaction results with orthopedic subspecialty.

\section{AUTHOR AFFILIATIONS}

1. Marshall University Joan C. Edwards School of Medicine, Huntington, West Virginia

\section{REFERENCES}

1. Bowling A. Mode of questionnaire administration can have serious effects on data quality. Journal of Public Health (Oxford, England). 2005;27(3):281-91.

2. Bowling A. Research methods in health: investigating health and health services. 4th ed. New York: McGraw Hill Education; 2014.

3. Gwaltney CJ, Shields AL, Shiffman S. Equivalence of electronic and paper-and-pencil administration of patient-reported outcome measures: a meta-analytic review. Value in health :the Journal of the International Society for Pharmacoeconomics and Outcomes Research. 2008;11(2):322-33.

4. Tsai TC, Orav EJ, Jha AK. Patient satisfaction and quality of surgical care in US hospitals. Annals of Surgery. 2015;261(1):2-8.

5. Kalisch BJ, Curley M, Stefanov S. An intervention to enhance nursing staff teamwork and engagement. The Journal of Nursing Administration. 2007;37(2):77-84.

6. Jha AK, Orav EJ, Zheng J, Epstein AM. Patients' perception of hospital care in the United States. The New England Journal of Medicine. 2008;359(18):1921-31.

7. Marshall GN, Hays RD, Mazel R. Health status and 
satisfaction with health care: results from the medical outcomes study. Journal of Consulting and Clinical Psychology. 1996;64(2):380-90.

8. Clark PA, Leddy K, Drain M, Kaldenberg D. State nursing shortages and patient satisfaction: more RNs--better patient experiences. Journal of Nursing Care Quality. 2007;22(2):119-27;quiz 28-9.

9. Fenton JJ, Jerant AF, Bertakis KD, Franks P. The cost of satisfaction: a national study of patient satisfaction, health care utilization, expenditures, and mortality. Archives of Internal Medicine. 2012;172(5):405-11.

10. Giordano LA, Elliott MN, Goldstein E, Lehrman WG, Spencer PA. Development, implementation, and public reporting of the HCAHPS survey. Medical Care Research and Review. 2010;67(1):2737.

11. Bickell NA, Neuman J, Fei K, Franco R, Joseph KA. Quality of breast cancer care: perception versus practice. Journal of Clinical Oncology. 2012;30(15):1791-5.

12. Kane RL, Maciejewski M, Finch M. The relationship of patient satisfaction with care and clinical outcomes. Medical Care. 1997;35(7):714-30.

13. Daly R. Unsatisfactory marks. Hospitals question use of HCAHPS in scoring for value-based purchasing. Modern Healthcare. 2011;41(33):30.

14. Goldstein E, Elliott MN, Lehrman WG, Hambarsoomian K, Giordano LA. Racial/ethnic differences in patients' perceptions of inpatient care using the HCAHPS survey. Medical Care Research and Review. 2010;67(1):74-92. 
